\title{
The Relationship between English Phonological Awareness of Chinese English Learners and Their English Skills*
}

\author{
$\mathrm{Min} \mathrm{Hu}$ \\ Southwest University of Political Science \& Law, Chongqing, China
}

\begin{abstract}
This study investigated the relationship between English phonological awareness (PA) of Chinese English learners and their three English skills (reading, spelling, and listening). Four-hundred college students participated in the study. The results of correlation and regression analyses demonstrated that: 1) overall PA correlated significantly with the three skills and predicted spelling strongly, listening intermediately, and reading weakly; 2) the three levels of $\mathrm{PA}$ had differential effects on English skills: reading was only significantly predicted by syllable awareness, spelling by onset-rhyme and phoneme awareness, and listening by all levels of PA; and 3 ) the predictive effects of tasks corresponded to the difficulty of the processing skill required by a task. This study has borne out a vital role of English PA in improving adult Chinese English learners' English skills.
\end{abstract}

Index Terms - phonological awareness, English skills, reading, spelling, listening

\section{INTRODUCTION}

To improve the English proficiency of Chinese English learners, language researchers and educators in China have been committed to exploring the factors that promote their English learning. Research has shown that phonological awareness (PA), vital to the development of learners' English proficiency, can predict their language skills such as reading, spelling, listening, and speaking, etc. (e.g., Ball \& Blanchman, 1988; Christensen, 1997; Liberman et al., 1974). PA refers to an ability to perceive and manipulate speech, encompassing three levels of skill: the shallow level of syllable awareness, the deep level of phoneme awareness, and the intermediate level of onset-rhythm awareness (Treiman, 1985). PA assessment uses a variety of tasks to examine different processing skills of the three levels of PA, including differentiation, detection, segmentation, blending, deletion, and substitution, etc.

Research (Cheung, 1999; Liberman et al., 1974; Treiman \& Baron, 1981) has found that children with strong PA are familiar with the grapheme and phoneme correspondence (GPC), with the help of which they can read letters and letter combinations or match spoken sounds with written symbols to recognize unfamiliar words. The more words they can recognize, the faster they can read and better they can comprehend. In the same way, children with a higher PA level tend to have a stronger word spelling skill. Drawing on the awareness of words' phonological structure and the pronunciation of familiar words, children can spell out written glyphs according to the GPC rules, thus memorizing more words (Yao, 2001). In addition, as a perceptive skill, listening requires individuals to receive, recognize, decode, and remember auditory symbols. During the listening process, individuals with better PA can quickly infer the words they have heard based on the GPC, thus improving their listening comprehension. Studies with either children or adults have yielded converging results that English PA plays an important role in the English learning of both native speakers and second language speakers.

Research on English-speaking children has revealed that word recognition and spelling are significantly correlated with PA (Gough et al., 1992; Share \& Stanovich, 1995; Wagner et al., 1994). Stainthorp et al. (2013) found that British kindergarten children's word spelling scores were positively associated with their mastery of the GPC rules. More research has manifested that PA can predict both the abilities to read and spell words and the overall reading skill (Bradley \& Bryant, 1978, 1983; Lunderberg et al., 1980; Wade-Woolley, 2016). In studies by Bradley and Bryant (1983) and Stanovich (2000), deficiency in PA led to children's literacy problem, which in turn led to the difficulty with reading. It has also been found that despite many other factors affecting children's reading skill (e.g., working memory, cognitive ability, or morphological awareness), PA still holds a potent impact: differences in children's PA skill give rise to differences in spelling and reading skills between them (Adams, 1990; Ball \& Blachman, 1991; Christensen, 1997; Cunningham, 1990; Goswami \& Bryant, 1990; Hatcher et al, 1994). Other studies have demonstrated that PA training can improve children's literacy (Ball \& Blachman, 1991; Cunningham, 1990; Eissa, 2013; Stanovich \& Siegel, 1994; Wagner \& Torgesen, 1987). Carson et al. (2013) found that New Zealand children under a year of regular PA training achieved significantly better word reading and spelling skills than untrained children.

\footnotetext{
${ }^{*}$ Sponsored by the Ministry of Education of PRC (13YJC740031) and Southwest University of Political Science \& Law (2013-XZRCXM006).
} 
Similar results have emerged in the research on Chinese English learners. The first line of research focuses on Cantonese-speaking children living abroad (Cheung et al., 2010; Gottardo et al., 2001) or in Hong Kong (McBride-Chang \& Ho, 2005; McBride-Chang \& Treiman, 2003; Yeung et al., 2013). The results consistently revealed that English PA training enhanced children's sensitivity to the GPC and thus their ability to read new words and that in spelling words, trained children made significantly less mistakes than those untrained. In Cheung's (1999) study with Hong Kong teenagers, the predictive effect of PA on word recognition occurred only to the younger group $(M=12.7)$, but not to the older group $(M=15.8)$. This finding may indicate that age has a mediating effect on English PA. The second line of research centers on English learners in Mainland China. Be it on children (Tao et al., 2007; Sun et al., 2015), adolescents (F. Wang, 2010; Wang et al., 2002), or adult students (Guan, 2009), research made clear that English PA was a strong predictor of word spelling and reading as well as the overall reading skill, with different levels of PA playing dissimilar roles. In specific, Dong and Wen (2010) found that onset-rhyme awareness had a predictive role in children's English spelling. Both Tao et al. (2007) and Yang and Zhang (2015) found that onset-rhyme awareness significantly predicted word recognition. In the study by Li et al. (2011), both onset-rhyme awareness and phoneme awareness accounted for the variance in word reading and spelling, more so in word spelling. Other research (Li \& Kang, 2015; Wu, 2006; Zeng \& Chen, 2010; Zhang \& Zhu, 2015) has yielded that English PA is significantly related to Chinese college students' listening performance.

The above studies on both English native speakers and Chinese English learners have demonstrated that English PA skill can improve such English skills as word reading and spelling, overall reading, and listening. Cheung (1999) has found that the facilitative role of PA weakens with age. Accordingly, the present study selected adult college students as participants to further explore whether the role of PA in English proficiency is limited by age. Furthermore, few researchers have investigated the relationships between PA and English reading, spelling, and listening skills in a single study. The study by Fracasso et al. (2016) is the only attempt, but they tested adult English native speakers, and their PA skill was assessed by word reading instead of widely accepted PA tasks; therefore, the results of their study have limitations. As a result, the present study aims to examine the relationship of overall English PA and its three levels of PA with three English skills of reading, spelling, and listening, and to investigate the role of different PA tasks (processing skills) in these three skills as well.

\section{RESEARCH QUESTION}

The specific research questions this study intends to explore are as follows:

1) What is the relationship between overall English PA and the three English skills?

2) Do different levels of PA play different roles in the three English skills? If so, how?

3) Do different tasks (processing skills) play different roles in the three English skills? If so, how?

\section{METHOD}

\section{A. Participants}

The participants were 400 Chinese college students $(\mathrm{M}=164 ; \mathrm{F}=236)$ with an average age of 20.4, randomly selected from second-year non-English majors in a Chinese university. They were all from intermediate-level English classes based on their scores on the English entrance examination administered upon their university entry.

\section{B. Materials}

English PA. The English PA test, audibly presented, assessed three levels of PA across four phonological skills (tasks), as Table I shows:

TABLE I.

THE ENGLISH PA TEST BY LEVEL OF PA AND TASK

\begin{tabular}{|c|c|c|c|}
\hline Task & Level of PA & Number of items & Score \\
\hline \multirow{3}{*}{ Oddity } & Syllable & 10 & 10 \\
\cline { 2 - 4 } & Onset-rhyme & 10 & 10 \\
\cline { 2 - 4 } & Phoneme & 10 & 10 \\
\hline \multirow{3}{*}{ Segmentation } & Syllable & 10 & 10 \\
\cline { 2 - 4 } & Onset-rhyme & 10 & 10 \\
\cline { 2 - 4 } & Phoneme & 10 & 10 \\
\hline \multirow{3}{*}{ Blending } & Syllable & 10 & 10 \\
\cline { 2 - 4 } & Onset-rhyme & 10 & 10 \\
\cline { 2 - 4 } & Phoneme & 10 & 10 \\
\hline \multirow{3}{*}{ Substitution } & Syllable & 10 & 10 \\
\cline { 2 - 4 } & Onset-rhyme & 10 & \\
\cline { 2 - 4 } & Phoneme & & 10 \\
\hline
\end{tabular}

English reading and listening. The participants' reading and listening skills were operationalized by their scores on the reading and listening sections, respectively, of their English final exam of last semester administered two months prior to the English PA test. The reading section included one fast-reading article and four normal-reading passages with 
a total score of 40 . The listening section consisted of ten short dialogues and three long passages with a total score of 30. Students read or listened to each material first and then answered its multiple-choice questions, each of which had one point.

English spelling. The spelling test comprised 20 English non-words, with mostly monosyllabic words and few disyllabic ones. The testing items were recorded by an English native speaker in the form of mp3 files. The participants were instructed to listen to one item and then spell it out. Every correctly spelt word counted one point.

\section{Procedure}

The English PA test was conducted in a quiet office, each session for approximately 40 minutes. The participants were divided into three groups, each with a different experimenter, who assessed them one by one. Before the test, the experimenter provided the instruction and practice; during the test, the participants listened to each item played using the Storm Player on the experimenter's laptop and then was given five seconds to give the answer, which was recorded by the recording app on the laptop. The spelling test was conducted one week later, and the three groups of participants were tested simultaneously in three different computer classrooms. The experimenter offered the instruction and practice first and then played each non-word using the Storm Player on the desktop in the classroom; the participants had five seconds to spell out this word on the answer sheet. The entire data collection took one month, and the final number available for data analysis was 347 samples.

\section{RESULTS}

\section{A. Correlation Analyses}

The correlations are displayed in Table II of overall PA, all three levels of PA, and all tasks with the three English skills. Overall PA had significant correlations with all skills (all $p<.001$ ), closest with spelling, followed by listening, and weakest with reading.

TABLE II.

CORRELATIONS BETWEEN PA AND ENGLISH SKILLS BY OVERALL PA, LEVEL OF PA, AND TASK

\begin{tabular}{|c|c|c|c|c|c|c|c|c|}
\hline & $\begin{array}{c}\text { Overall } \\
\text { PA }\end{array}$ & $\begin{array}{c}\text { Syllable } \\
\text { awareness }\end{array}$ & $\begin{array}{c}\text { Onset-rhyme } \\
\text { awareness }\end{array}$ & $\begin{array}{l}\text { Phoneme } \\
\text { awareness }\end{array}$ & Oddity & $\begin{array}{l}\text { Segmen- } \\
\text { tation }\end{array}$ & Blending & $\begin{array}{l}\text { Substi- } \\
\text { tution }\end{array}$ \\
\hline Reading & $0.27 * * *$ & $0.26 * * *$ & $0.19 * * *$ & $0.20 * * *$ & $0.14 * *$ & 0.10 & $0.26 * * *$ & 0.23 *** \\
\hline Spelling & $0.48 * * *$ & $0.35 * * *$ & 0.45 *** & $0.34 * * *$ & $0.13 *$ & $0.30 * * *$ & $0.41 * * *$ & $0.43 * * *$ \\
\hline Listening & $0.42 * * *$ & $0.36 * * *$ & $0.33 * * *$ & $0.34 * * *$ & 0.10 & $0.14 * *$ & $0.43 * * *$ & $0.44 * * *$ \\
\hline
\end{tabular}

All three levels of PA correlated significantly with the three skills (all $p<.001$ ). Comparable correlations existed between syllable awareness and both spelling and listening; their associations were stronger than that between syllable awareness and reading. A similar situation happened to phoneme awareness. Onset-rhyme awareness correlated strongly with spelling, intermediately with listening, and least with reading. The results revealed that the correlations between reading and syllable awareness was much higher than those between reading and onset-rhyme awareness or phoneme awareness; that spelling was most closely related to onset-rhyme awareness; and that the correlations between listening and all levels of PA were comparable.

The correlations between four tasks and the three skills were slightly weaker than those between three levels of PA and the skills. Reading did not correlate significantly with segmentation; its correlation with oddity was weaker than with blending or substitution. Spelling correlated significantly with all levels of PA: least with oddity, intermediately with segmentation, and strongly with blending or substitution. A significant correlation did not appear between listening and oddity, and its correlation with segmentation was weaker than with blending or substitution. Taken together, the three skills were more closely associated with blending and substitution than with oddity and segmentation.

\section{B. Regression Analyses}

First, overall PA was entered as the independent variable to perform a one-way regression analysis on the scores of the three skills (as dependent variables), and then three levels of PA and tasks (processing skills) as independent variables to perform stepwise regression analyses. The results showed (see Table III) that overall PA explained $7 \%$ of the variance in reading, $23 \%$ in spelling, and $18 \%$ in listening. Although the predictive power of overall PA seemed to be weak, the predictive effects on the three skills were all significant (all $p<.001)$.

TABLE III.

REGRESSIONS FOR PREDICTING READING, SPELLING, AND LISTENING FROM OVERALL PA

\begin{tabular}{|c|c|c|c|c|c|c|}
\hline & $B$ & $\beta$ & $t$ & $R^{2}$ & $F$ \\
\hline Reading & 0.08 & 0.27 & 5.12 & 0.07 & 26.214 & .000 \\
\hline Spelling & 0.09 & 0.48 & 10.04 & 0.23 & 100.726 \\
\hline Listening & 0.19 & 0.42 & 8.66 & 0.18 & 75.054 \\
\hline
\end{tabular}


When level of PA was the independent variable (see Table IV), only syllable awareness contributed significantly to reading. As far as spelling was concerned, onset-rhyme awareness was the strongest predictor, followed by phoneme awareness, but syllable awareness had no significant predictive effect. In terms of listening, all three levels of PA exerted significant predictive effects. When task was the independent variable (see Table V), only the blending task significantly predicted reading. Only oddity did not significantly predict spelling; blending and substitution were stronger predictors than segmentation. In terms of listening, blending and substitution accounted for variance while oddity and segmentation did not.

TABLE IV...

REGRESSIONS FOR PREDICTING READING, SPELLING, AND LISTENING FROM LEVELS OF PA

\begin{tabular}{|c|c|c|c|c|c|c|}
\hline & \multicolumn{2}{|c|}{ Reading } & \multicolumn{2}{|c|}{ Spelling } & \multicolumn{2}{|c|}{ Listening } \\
\hline & $\beta$ & $t$ & $\beta$ & $t$ & $\beta$ & $t$ \\
\hline Syllable awareness & 0.26 & $2.84 * * *$ & 0.11 & l & 0.19 & $3.05^{* *} *$ \\
\hline Onset-rhyme awareness & 0.08 & l & 0.38 & $7.10 * * *$ & 0.18 & $3.02 * *$ \\
\hline \multirow[t]{2}{*}{ Phoneme awareness } & 0.10 & I & 0.17 & $3.23 * *$ & 0.16 & $2.62 * *$ \\
\hline & \multicolumn{2}{|c|}{$F=24.598, p=.000 ; R^{2}=.067$} & \multicolumn{2}{|c|}{$F=51.056, p=.000 ; R^{2}=.229$} & \multicolumn{2}{|c|}{$F=25.154, p=.000 ; R^{2}=.180$} \\
\hline
\end{tabular}

TABLE V

REGRESSIONS FOR PREDICTING READING, SPELLING, AND LISTENING FROM TASKS

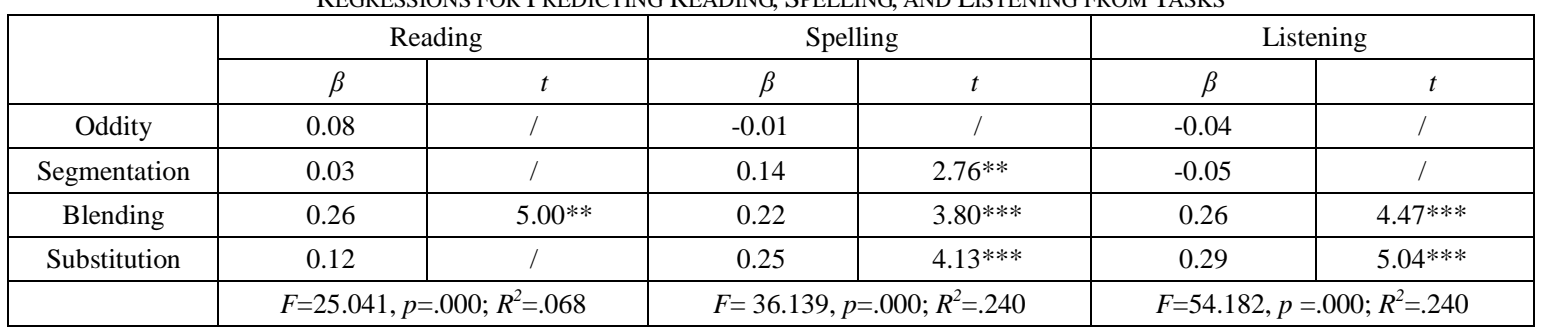

\section{DISCUSSION}

As for Question 1, the results showed that overall PA correlated significantly with the three skills and that its prediction of spelling was the strongest and of reading weakest. In the studies by Li et al. (2011) with Chinese primary school students and by Fracasso et al. (2016) with adult English native speakers, PA was also more closely related to spelling than to reading. Our findings further confirm that PA has different effects on different English skills. This difference can be explained by Forster's (1976) Autonomous Search Model, in which learners decipher the meaning of words through different independent channels, including the GPC rules, phonological knowledge, and semantic knowledge, etc. First, the basis of the reading skill is word recognition. Since English is an alphabetic language, a learner with strong PA can transfer a written symbol to a phonetic one based on the GPC rules to read a word. However, the present study employed reading passages to test reading, which required the use of semantic knowledge. Therefore, even if the participants knew the pronunciation of words, it would be difficult for them to link the word form with the word meaning through visual recognition to understand the meanings of sentences or paragraphs. This research design may explain the lowest correlation between PA and reading in this study. It may also explain why PA only predicted $8 \%$ of the variance in reading, while in previous studies (e.g., Wagner et al., 1994) employing word recognition to test reading, the prediction power was generally much stronger. Furthermore, in this study, the participants could not resort to semantic knowledge for word spelling because all stimuli were fake words created according to English phonological rules. After hearing a word, they could only convert a sound to a written symbol in light of the GPC rules. Finally, in terms of listening, the participants needed to activate both phonological and semantic knowledge, relying on semantic storage to identify familiar words and on phonological rules to decode unfamiliar words. It follows that the different effects of English PA on the three English skills were proportional to the latter's demand for the former.

As for Question 2, the results revealed that different levels of PA played different roles in different language skills. In terms of reading, only syllable awareness was significantly predictive. The results of previous studies, however, showed that onset-rhyme awareness had a significant impact on beginning readers (Bryant et al., 1990), but as their reading skill increased, children depended on the deep level of phoneme awareness to read words (Li et al., 2011; Sun et al., 2015). The reason for the difference in the results may be due to different research methods. Previous studies mainly examined word reading while the present study tested reading comprehension of paragraphs. Paragraph reading required the participants to understand the word as a whole in the context, so they needed to draw more on the shallow level of syllable awareness to quickly decode the word. Yang and Zhang (2015) also examined the relationship between Chinese college students' reading skill and three levels of PA by means of paragraph reading, and their research yielded that onset-rhyme awareness had the most significant correlation with reading. Nonetheless, their study employed dissimilar tasks to measure different levels of PA, and only conducted correlation analyses without regression analyses, so these 
differences may lead to differences in the results.

In terms of spelling, onset-rhyme awareness was the strongest predictor while syllable awareness had no significant predictive effect. This finding is consistent with the results of the study by Dong and Wen (2010), corroborating the prominent role of onset-rhyme awareness in Chinese learners' spelling skill. Studies with English-speaking children (e.g., Hulme et al., 2002) found that phoneme awareness was the strongest predictor of their spelling skill, though. According to Dong and Wen (2010: 148), the discrepancy in the results is related to the Chinese participants' L1 phonological experience: Pinyin features a combination of onsets and rhymes, similar to the CV structure in English, so this level of PA exerted the strongest effect on Chinese learners' spelling. In terms of listening, the three levels of PA were all significantly related to and predictive of listening, a result which demonstrated the importance of PA to the listening skill. Unlike reading and spelling, listening requires listeners to decode the auditory cue in the shortest possible time and to build a sound-and-form relationship through the GPC rules. Although the listening test in this study examined the overall comprehension of sentences, decoding words was the first step. In view of various word structures, the participants would activate different levels of PA based on diversified phonological structures of words in the process of listening, so all levels of PA had significant effects on listening.

As for Question 3, the role of tasks (processing skills) is manifested in three aspects. First, the task had the strongest predictive effect on spelling and the weakest on reading. This result corresponds to the degree of demand for PA by the three skills. Second, different English skills invoke different processing skills. Only the blending task significantly predicted reading; only the oddity task failed to predict spelling significantly; and the oddity and segmentation tasks did not significantly predict listening. Third, the four tasks ranked as follows according to their prediction power: blending (strongest) > substitution > segmentation > oddity. This order is line with the difficulty order of the four tasks. The oddity task entails an ability to differentiate sounds, which is the easiest; the segmentation task to divide the sounds and substitution to replace the sounds, which are comparatively harder; and blending to combine sounds, which is the most difficult. It follows that the task with a harder processing skill exerts a greater effect on English skills. That is why the simplest oddity task had no significant predictive effect on spelling or listening, and the hardest blending task significantly predicted reading while the other three easier tasks failed to do so.

In summary, the facilitative role of English PA in English skills has been reinforced; nonetheless, the exploration of the relationship between the two should not revolve merely around the simple question of whether the former promotes the latter, but should be how PA differentially impacts the three English skills. If PA is treated as a holistic skill, then our conclusion is that overall PA has differential effects on the three skills, with the strongest prediction on spelling and the weakest on reading. But if we look at different levels of PA, we conclude that the relationship between the two is complex. The three levels of PA have different phonological structures and units of increasing difficulty, and the language processing of the three skills and their need for PA also vary, so the roles of the three levels of PA in English skills differ from those of overall PA. In this study, syllable awareness had the strongest predictive power on reading, and onset-rhyme awareness on spelling, but all levels of PA on listening. Previous studies (e.g., Li et al., 2011; Tao et al., 2007; Yang \& Zhang, 2015) also found that different levels of PA played differential roles in spelling and reading skills, but their findings might be influenced by the task type because the tasks they used were neither uniform nor varied. For example, Yang and Zhang (2015) employed the blending and segmentation tasks to test syllable awareness; blending and oddity onset-rhythm awareness; and blending, deletion, segmentation, and isolation phoneme awareness. Both Tao et al. (2007) and $\mathrm{Li}$ et al. (2011) used merely the deletion task to examine the three levels of PA. As we all know, there are assorted PA tasks with various difficulty and different requirements for the processing skills of PA. Therefore, to accurately compare the roles of different levels of PA in English skills, the present study employed the same four tasks of increasing difficulty for all levels of PA. Additionally, the results showed that the predictive effects of tasks on the three English skills were modified by the difficulty of a specific task. It follows that a comprehensive examination of the relationship between PA and English skills should assess the relationships of overall PA, levels of PA, and tasks (processing skills) with different English skills.

The present study has yielded that English PA, whose impact did not atrophy with age, remained a potent predictor of Chinese adult English learners' reading, spelling, and listening skills. Chinese researchers (e.g., Hu, 2016; Li et al., 2011; Wu, 2006) have always advocated that in the early stage of English learning in primary school, English teachers should provide regular phonics teaching to cultivate beginners' awareness of speech units and the GPC rules to promote their word reading and spelling. The real situation is not optimistic, though. There has been scarce attention paid to the phonics teaching in primary school in China, and English teaching in secondary school is mainly exam-oriented. At the university level, many students do not even recognize the phonetic symbols, let alone having basic PA skill (Y. Wang, 2010). This deficiency has resulted in a low level of ability to pronounce, recognize, and spell words and poor listening skill. The author, therefore, calls on college English teachers to assess their students' PA upon university entry to uncover problems in time and to come up with effective teaching interventions. When necessary, the teachers can add phonological knowledge and GPC rules to their English teaching as well as employ a variety of tasks, especially difficult ones (such as blending and deletion, etc.), to develop their students' PA. Our research reveals that the effect of PA on English skills is not undermined by age. Hence, it is still not late to cultivate Chinese adult learners' English PA in the view of promoting their English skills. 


\section{CONCLUSION}

The present study has yielded three findings. First, overall English PA had significant correlations with English reading, spelling, and listening. Its predictive effect on spelling was the strongest, followed by listening, and on reading the weakest. This result is associated with the degree of demand for PA by different English skills. Second, different levels of PA had differential effects on the three skills. Syllable awareness contributed significantly to reading; onset-rhyme awareness predicted spelling most; and all three levels of PA significantly predicted listening. This result may be affected by factors such as testing formats or the participants' phonological experience. Third, based on their predictive power, the four tasks ranked as blending (strongest) > substitution > segmentation > oddity. This order is consistent with the difficulty of the processing skills required by a task; the more difficult the task, the stronger predictable effect on English skills.

This study bears out a vital role of English PA in promoting three English skills, providing pedagogical and theoretical implications. Pedagogically, previous studies only explored the effects of different levels of PA on the three English skills while ignoring the influence of PA tasks. Therefore, the results of this study can help teachers understand the relationships between tasks and different English skills, and choose tasks of increasing difficulty to train different levels of PA. Theoretically, previous research mainly studied the relationship between PA and only one English skill. This study incorporated three English skills and investigated the differences in the effects of different levels of PA and tasks (processing skills) on these skills. In addition, unlike previous studies, this study designed the same tasks for different levels of PA to ensure the comparability of results. Such innovations in the research method can guide future research.

Admittedly, this study is not without limitations. So far, the research on the roles of PA and its different levels on English skills has not yielded converging results. The discrepancies are likely caused by factors such as testing tasks, the type of English skills, and testing formats, etc. Future research thus must consider the potential influence of the above factors on research results; so must it more extensive sampling, more tasks of various difficulty (e.g., positioning, counting, or deletion, etc.), and other English skills (e.g., sentence dictation, oral expression, or writing, etc.). Future research should also take into account the interaction between level of PA and task (processing skill) in order to explore the relationship between English PA and English skills more comprehensively and accurately.

\section{REFERENCES}

[1] Adams, M. J. (1990). Beginning to read: Thinking and learning about print. Cambridge, MA: MIT Press.

[2] Ball, E. \& B. Blachman. (1988). Phoneme segmentation training: Effect on reading readiness. Annals of Dyslexia, 38, $208-225$.

[3] Bradley, L. \& P. E. Bryant. (1978). Difficulties in auditory organization as a possible cause of reading backwardness. Nature, 271, 746-747.

[4] Bradley, L. \& P. E. Bryant. (1983). Categorizing sounds and learning to read-a causal connection. Nature, 301, 419-421.

[5] Bryant, P. E., M. MacLean, L. L. Bradley \& J. Crossland. (1990). Rhyme and alliteration, phoneme detection, and learning to read. Developmental Psychology, 26, 429-438.

[6] Carson, K. L., G. T. Gillon \& T. M. Boustead. (2013). Classroom phonological awareness instruction and literacy outcomes in the first year of school. Language, Speech, and Hearing Sciences in Schools, 44, 147-160.

[7] Cheung, H. (1999). Improving phonological awareness and word reading in a later learned alphabetic script. Cognition, 70, $1-26$.

[8] Cheung, H., K. Chung, S. Wong, C. McBride-Chang, T. B. Penney \& C. S. H. Ho. (2010). Speech perception, metalinguistic awareness, reading, and vocabulary in Chinese-English bilingual children. Journal of Educational Psychology, 102, 367-380.

[9] Christensen, C. A. (1997). Onset, rhymes, and phonemes in learning to read. Scientific Studies of Reading, 1, 341-358.

[10] Cunningham, A. E. (1990). Explicit versus implicit instruction in phonemic awareness. Journal of Experimental Child Psychology, 50, 429-444.

[11] Dong, L. \& S. Wen. (2010). The relationship between Chinese children's English phonological awareness and their spelling. Studies of Psychology and Behavior, 8, 146-149.

[12] Eissa, M. A. (2013). The effectiveness of a phonological awareness training intervention on pre-reading skills of children with mental retardation. International Journal of Psycho-Educational Sciences, 2, 12-22.

[13] Forster, K. (1976). Accessing the mental lexicon. In R. J. Wales \& E. Walker (Eds), New approaches to language mechanisms. Amsterdam: North-Holland, 257-287.

[14] Fracasso, L. E., K. Bangs \& K. S. Binder. (2016). The contributions of phonological and morphological awareness to literacy skills in the adult basic education population. Journal of Learning Disabilities, 49, 140-151.

[15] Goswami, U. \& P. E. Bryant. (1990). Phonological skills and learning to read. London: Erlbaum.

[16] Gottardo, A., B. Yan, L. Siegel \& L. Wade-Woolley. (2001). Factors related to English reading performance in children with Chinese as a first language: More evidence of cross-language transfer of phonological processing. Journal of Educational Psychology, 93, 530-542.

[17] Gough, P. B., L. C. Ehri \& R. Treiman (eds.) (1992). Reading acquisition. Hillsdale, NJ: Erlhaum.

[18] Guan, J. (2009). The study on the correlativity between English phonological awareness and reading competence of university students. Master thesis. Harbin University of Science and Technology.

[19] Hatcher, P. J., C. Hulme \& W. Ellis. (1994). Ameliorating early reading failure by integrating the teaching of reading and phonological skills: The phonological linkage hypothesis. Child Development, 65, 41-57.

[20] Hu, W. (2016). Strategies on developing primary school students' phonological awareness in phonics teaching. New Curriculum Research, 3, 86-87. 
[21] Hulme, C., P. J. Hatcher, K. Nation, A. Brown, J. Adams \& G. Stuart. (2002). Phoneme awareness in a better predictor of early reading skill than onset-rime awareness. Journal of Experimental Child Psychology, 82, 2-28.

[22] Li, P., S. Tao \& Q. Dong. (2011). The roles of phonological awareness in English word reading and spelling among Mandarin-speaking children. Psychological Development and Education, 4, 388-393.

[23] Li, S. \& Y. Kang. (2015). The effect of PA training on English listening. Yalu River, 3, 1008-1009.

[24] Liberman, I. Y., D. Shankweiler, F. W. Fisher \& B. Carter. (1974). Explicit syllable and phoneme segmentation in the young children. Journal of Experimental Child Psychology, 18, 201-212.

[25] Lundberg, I., A. Olofsson \& S. Wall. (1980). Reading and spelling skills in the first school years predicted from phonemic awareness skills in kindergarten. Scandinavian Journal of Psychology, 21, 159-173.

[26] McBride-Chang, C. \& C. S. Ho. (2005). Predictors of beginning reading in Chinese and English: A 2-year longitudinal study of Chinese kindergartners. Scientific Studies of Reading, 9, 117-144.

[27] McBride-Chang, C. \& R. Treiman. (2003). Hong Kong Chinese children learn to read English analytically. Psychological Science, 14, 138-143.

[28] Share, D. L. \& K. E. Stanovich. (1995). Cognitive processes in early reading development: Accommodating individual differences into a model of acquisition. Issues in Education: Contributions from Educational Psychology, 1, 1-57.

[29] Siegel, L. S. \& E. B. Ryan. (1988). Development of grammatical-sensitivity, phonological and short-term memory skills in normally achieving and subtypes of learning disabled children. Developmental Psychology, 24, 28-37.

[30] Stainthorp, R., D. Powell \& M. Stuart. (2013). The relationship between rapid naming and word spelling in English. Journal of Research in Reading, 36, 371-388.

[31] Stanovich, K. E. (2000). Progress in understanding reading: Scientific foundations and new frontier. New York: Guiford.

[32] Stanovich, K. E. \& L. S. Siegel. (1994). The phonotypic performance profile of reading-disabled children: A regression-based test of the phonological-core variable-difference model. Journal of Educational Psychology, 86, 24-53.

[33] Sun, B., B. Zhu, J. Chen \& H. Zhu. (2015). The effects of phonological awareness training on the reading performance by child EFL learners in China. Chinese Journal of Applied Linguistics, 38, 339-354+369.

[34] Tao, S., Y. Feng \& W. Li. (2007). The roles of different components of phonological awareness in English reading among Mandarin-speaking children. Psychological Development and Education, 2, 82-92.

[35] Treiman, R. (1985). Phonemic analysis, spelling, and reading. In T. Carr (Ed.), New directions for child development: The development of reading skills. San Francisco: Jossey-Bass, 5-18.

[36] Treiman, R. \& J. Baron. (1981). Segmental analysis ability: Development and relationship to reading ability. In G. E. MacKinnon \& T. G. Waller (Eds.), Reading research: Advances in theory and practice (vol. 3). NY: Academic Press, 159-198.

[37] Wade-Woolley, L. (2016). The contributions of prosodic and phonological awareness to reading. Reading and Writing, 29, $1-12$.

[38] Wagner, R. K. \& J. K. Torgesen. (1987). The nature of phonological processing and its causal role in the acquisition of reading skills. Psychological Bulletin, 101, 192-212.

[39] Wagner, R. K., J. K Torgesen \& C. A. Rashotte. (1994). Development of reading-related phonological processing abilities: New evidence of bidirectional causality from a latent variable longitudinal study. Developmental Psychology, 30, 73-87.

[40] Wang, F. (2010). A Study of the relation between phonological awareness and reading comprehension ability. Journal of Jinhua Polytechnic, 10, 26-30.

[41] Wang, Y. (2010). Reflection on teaching English phonics in middle schools from the perspective of university freshmen's phonetic competence. Curriculum, Teaching Material, and Method, 30, 56-60.

[42] Wang, Y., C. Lin \& G. Yu. (2002). Relationship between phonological skill and reading comprehension ability among poor English learners. Acta Psycholgica Sinica, 34, 279-283.

[43] Wu, L. (2006). The facilitation of phonological awareness for the increase of listening vocabulary. Journal of Wuhan University of Science and Engineering, 19, 95-97.

[44] Yang, X. \& Z. Zhang. (2015). Correlation study of English major's phonological awareness and their English reading ability. Journal of Zhaotong University, 37, 99-102.

[45] Yao, Y. (2001). The implications of Western phonological awareness research for education in China. Journal of Ningbo University (Educational Science), 23, 9-12.

[46] Yeung, S. S. S., L. S. Siegel \& C. K. K. Chan. (2013). Effects of a phonological awareness program on English reading and spelling among Hong Kong Chinese ESL children. Reading \& Writing, 26, 681-704.

[47] Zeng, Y. \& S. Chen. (2010). The correlation between English phonological awareness and listening scores. Kaoshi Zhoukan, 24 98-99.

[48] Zhang, S. \& J. Zhu. (2015). The effect of PA training on the improvement of listening. English Teachers, 7, 32-38.

Min Hu is an Associate Professor of English at the School of Foreign Languages, Southwest University of Political Science \& Law, China. She obtained her Ph.D. degree in English from Auburn University, USA. She specializes in second language acquisition and teaching English as a foreign language. 